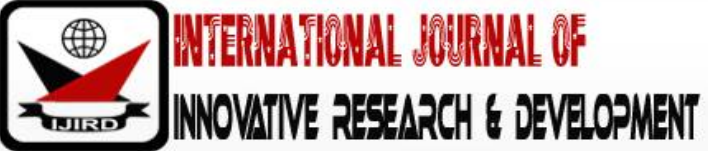

ISSN 2278 - 0211 (Online)

\section{An Assessment of the Impact of a Multimedia Courseware on the Teaching of Creative Arts in Ghanaian Basic Schools}

\begin{tabular}{c} 
Victor Quaynortey-Nyumu Teye \\
Lecturer, Department of Graphic Design, University of Education, Winneba, Ghana \\
PatriquedeGraft-Yankson \\
Senior Lecturer, Department of Graphic Design, University of Education, Winneba, Ghana \\
Ephraim Quaynor Teye \\
IT Technician, Division of Academic Affairs, University of Education, Winneba, Ghana \\
\hline
\end{tabular}

\begin{abstract}
:
The teaching of Creative Arts in Ghanaian Basic Schools is fraught with numerous challenges which negatively affect lesson preparation and delivery. Paramount among the challenges is the lack of training on how to teach the subject. As a result, many teachers use the contact hours allotted for creative arts for doing other things. This study was conducted to find out the impact of a multimedia courseware developed as a technological innovation to aid creative arts teachers in acquiring the relevant knowledge and skills for teaching the subject. The case study research design was employed for the study which involved 30lower primary class teachers in the Effutu Municipal Area in Ghana. Focused group interviews were conducted to collect data from the participants. The data was analyzed interpretively, with narrations from the comments made by the participants. The result of the study showed that generalist teachers in Ghanaian basic schools lack the competence in teaching the creative arts. Also, the use of the multimedia courseware had a positive influence on the teaching strategies of the teachers. It was concluded that the impact of a multimedia courseware on the teaching of creative arts in basic schools was very strong and positive. The study recommended that the Ghana Education Service should engage the services of multimedia courseware developers to design courseware for creative arts teachers in basic schools.
\end{abstract}

Keywords: Multimedia courseware, creative arts, generalist teachers, Ghanaian basic schools

\section{Introduction}

Technology is propelling teaching and learning activities worldwide. Teaching in the creative arts classroom demands very creative activities to make it enjoyable for everyone. With the advent of technology, teaching and learning today has become so diversified that, many lessons could be taught virtually through distance learning platforms, with teaching and learning resources becoming up-loadable and installable unto mobile devices for easy access and retrieval. Feats such as these have made the use of technology one of the best ways by which knowledge can be disseminated worldwide, thereby making the use of technology applications important means of boosting the interest of both teachers and students in teaching and learning. An interactive multimedia courseware can reduce or eliminate most of the problems such as omissions and abstractions associated with the teaching of Creative Arts in Ghanaian basic schools, which seems to have suffered a lot of pedagogical misinterpretations in the hands of 'untrained' teachers since its inception.

Creative Arts is a course introduced into the basic school curriculum in the 2007/2008 academic year after the implementation of the Anamuah-Mensah Educational Reforms. The Creative Arts curriculum covers the visual arts (drawing, weaving, carving, modeling, casting and sewing), performing arts (music, dance and drama) and literary arts (poetry, recitals). According to the National Council for Curriculum and Assessment (NaCCA) of Ghana (2007), Creative Arts in the primary school curriculum is meant to transmit, promote and preserve the culture of the nation, and also to develop children's creative capacities and enable them express themselves freely.

However, observation from preliminary investigations by the researchers over a period of two years revealed that this NaCCA'sgoal may not be realized for several reasons. These include the fact that most of the contact hours meant for Creative Arts are used for other purposes such as copying teaching notes of other subjects, marking class assignments, and resting. It was revealed that teachers engaged in such activities because they lacked the necessary knowledge and skills for teaching the creative art subject. According to some of these teachers, teaching Creative Arts demands a lot of skills training. Also, there are issues about the availability of textbooks, and other tools and materials which teachers need to effectively teach. Thissituation is however not peculiar to Ghanaian basic school teachers.Nilson, Fetherston, McMurray and Fetherston (2013) have reported that many Creative Arts teachers in the world lack the requisite skills and the understanding, knowledge and confidence to teach the subject simply because they are generalist teachers. Also, Alter, Hays and O'Hara (2009) indicated earlier that when it comes to the teaching and learning of Creative Arts in the primary 
schools, generalist teachers are compelled to teach what they do not know and are not comfortable with. Therefore, most of these teachers tend to use the teaching period for other activities.

It is important to note that Creative Arts in Ghana has been handicapped from its inception, to the extent that generalist teachers who are trained from the Colleges of Education, receive training to teach all subjects in the basic schools, except Creative Arts. Therefore, these teachers lack the competence required for teaching the subject. With the prominence given to the creative arts in the new basic school curriculum, the seriousness of these deficiencies become more pronounced, and therefore calls for some attention and action. These authors therefore that a thoughtfully designed user-friendly multimedia courseware wouldhelplower primaryclass teachers in Ghanaian basic schools to acquire the relevant knowledge and skills for teaching Creative Arts, with the purpose of assessing the impact of the multimedia courseware on the teaching of Creative Arts.

\section{Understanding Multimedia Courseware}

Multimedia courseware is the use of multiple media such as text, images, animation, audio, video and other related media clips in relation to time and space, to produce an instructional material using appropriate and approved course content into a course. Multimedia merges multiple levels of learning into an educational tool that allows for diversity in curricula presentation in almost all levels of education. The integration of these media in teaching assists teachers in blending subject matter with software engineering to produce an interactive system, thus harnessing the benefits of a variety of elements and putting them together to create an interesting and user-friendly educational software.

Often, a multimedia courseware is used to assist teachers to teach theoretical lessons in a practical fashion, to improve the understanding of concepts that are learned. Multimedia is the exciting combination of computer hardware and software that allows for the integration of video, animation, audio, graphics, and text resources to develop effective presentations on an affordable desktop computer (Gunawardhana \& Palaniappan, 2016). It has also been explained to mean any electronic learning material that could be an entire package with various lessons, tests, other materials needed and it could be displayed in the form of text, video, sound, and various forms of animations (Ussher, Damoah, Ansong, Quarshie, Adjetey, Poakwah, 2014).

Teaching and learning demand full concentration to aid the understanding of what is being learnt, with the fundamental purpose of bringing change in the learner (Tebabal \& Kahssay, 2011). This change would be manifested in the learner during the teaching activity. In teaching, some learners will have to create a mental picture or imagination of the concept being taught because they might be abstract in nature. For such abstract concepts to be easily understood by learners, the multimedia courseware approach is considered to be appropriate in the classroom, for better expression and understanding.

There are several factors that underscore the relevance of multimedia courseware in the teaching of creative arts in Ghanaian basic schools. These factors could either be intrinsic or extrinsic. The intrinsic conditions are largely dependent on the psychological framework of the learner, which can also translate into the performance or behaviour of the learner, whiles the extrinsic factors are normally dependent on the resources and procedures that are adopted and used during teaching and learning activities. There are numerous benefits that underpin the relevance of using multimedia courseware for teaching creative arts in Ghanaian basic schools. Prominent among which is its contribution to improvements in teaching and learning outcomes.

Many scholars over the years have agreed that, using interactive multimedia for teaching in the classroom pays off more than the textbook and lecture approach of teaching. It has been noted that, learners enjoy lessons with multimedia materials and therefore increase their learning. Najjar (1998) confirmed that learning was higher when information was presented via computer-based multimedia systems than traditional classroom lectures. To further argue out the essence of multimedia in learning, Joshi (2012) states that using of multimedia in classroom cannot be denied anymore. Using multimedia will make it possible for teachers to give more opportunities to their students to enjoy lessons. Teye (2012) noted that using multimedia courseware can benefit both teachers and learners in the areas of teaching and learning, research, and service. The most commonly stated goal of multimedia courseware is to improve student learning by improving upon class attendance and preparedness, clearer comprehension of content, more active participation during classes, increased peer/collaborative learning, better learning and higher retention rate, as well as greater learner satisfaction.

Again, the fundamental goal of all multimedia courseware is to improve teaching effectiveness. This can be achieved in at least two ways. The first relates to the use of learner response systems (embedded in multimedia courseware systems) which make it possible for immediate feedback from all learners. This timely feedback allows the teacher to better judge whether and how to amplify, clarify, or review points as the case may be. According to Taras (2003), feedback is an important part of the learning cycle thatmust be encouraged for better classroom interaction and participation. Secondly, multimedia courseware helps teachers to meet the unique needs of each learner in the classroom. This is because multimedia courseware takes away the one-size-fits-all approach to teaching, thereby meeting the needs of all learners, since the interests, attention spans and cognitive abilities of each learner differ from others (Felder \& Brent, 2005).

Multimedia courseware also enhances flexibility in the creative arts classroom speeds up knowledge and skill acquisition. Knowledge and skills in the creative arts can be acquired more easily and efficiently when learners are given room to operate under little supervision to study at their own pace, with necessary precautions. This flexibilitymakes learning easy and fun. Also, multimedia courseware presents true-life situations that learners often face in their day-to-day activities. Practical learners, learn best when they are faced with real situations or problems that have real life consequences. Situational stimulations, video stimulation or simple animations allow learners to learn-by-viewing, learn- 
by-doing, and learn-by-coaching. These learning styles are effective for developing practical skills and increasing information retention in learners. Because a multimedia courseware is an embodiment of lively, practical and interesting media elements, its application in the creative arts classroom makes teaching and learning very practical (Fu, Menzies, \& Shen, 2016).

Additionally, multimedia courseware keeps learners interested in the lessons being taught due to the excitement and satisfaction they get from the courseware. This excitement encourages learners to return to the program again and again. When learners become very interested in a learning activity, their performances increase from time-to-time and their confidence and mastery over the learnt subjects is also boosted significantly. This is confirmed by Fletcher (2000) and Wren (2008) who have noted that through continuous practice, learning is absorbed and integrated into daily performance. Also, learner satisfaction and better performance are achieved using multimedia courseware. According to Judson and Sawada (2002), learners perform better when multimedia or instructional technology is deployed in lessons. This is because multimedia courseware promotes learner attentiveness and personal understanding and satisfaction. It is important to underscore the point these attributes are critical to the successful learning of concepts in the creative arts, hence the relevance of adopting multimedia in teaching the creative arts.

\section{Methodology}

This qualitative study adopted the case study design, with the aim of assessing the impact of an intervention on the performance of the study participants. A total of 30lower primary class teachers were sampled using the stratified sampling technique, from a population of 51lower primary class teachers from 17 public primary schools in the Effutu Municipal Area in Ghana. The study was conducted in the first term of the 2018/2019 academic year.

In collecting data for the study, the researchers sought permission from the various headteachers of the schools from which the participants were sampled from, as well as the teachers who were sampled to participate in the study. This was done to get their cooperation and assistance. Creswell (2012) states that it is important to respect the site where research takes place, by obtaining permission before entering the research site. Permission to the site was facilitated by an introductory letter the researchers presented to the various headteachers of the schools. A pre-visit was made by the researchers to each school, to explain the purpose of the study to participants.

In implementing the intervention, which lasted for nine weeks, each participant was granted access to the online multimedia courseware, to watch and learn how best to effectively teach the creative arts. Meetings between the participants and the researchers were also held every fortnight, to enable the participants ask questions or seek clarifications on the project.

Focus group discussions involving 5 groups which consist of 6 participants in each group was conducted, spanning a period of two weeks. The researchers used focus group interviews because it allowed participants to speak out so that the researchers can learn what the range of views of participants are, in order to come out with all-embracing, rather than individual views of a phenomena (Bogdan \& Biklen, 2007; Cohen, Manion \& Morrison, 2007). Each discussion session lasted between 30 to 45 minutes, and was tape recorded with the permission of the participants and transcribed for analysis. Before analysis of the data, the researchers scheduled another meeting with the focus groups, where the transcripts were read to the participants to confirm that the transcripts represented the views they shared.

The data was analyzed interpretatively using narrative themes from the interview data. The transcripts of the interview data were coded for identification of responses from the various groups. All groups were assigned numbers (Group 1, Group 2, Group 3, Group 4 and Group 5). Fraenkel and Wallen (2009) noted that the first step in coding data is to assign identity numbers to every group from whom data has been collected. Further, colourschemes were used to code the themes that emerged from the focused group interview, for the purpose of categorization of themes. According to Bogdan and Biklen (2007), coding allows for the categories and patterns emerging from data to be decided in advance, and facilitates the interpretation of smaller units, since the analysis begins with the researcher reading all of the data to gain the sense of the whole. Finally, verbatim expressions of the participants' comments were used in reporting the data where necessary.

For ethical reasons, the researchers sought the consent of participantsto voluntarily participate in the study. The researchers explained to participants that their anonymityand confidentiality was guaranteed. It was ensured that participants understood the purpose of the study, and also treated the rights of the participants with utmost care. Again, the researchers sought the permission of participants to use the tape recorder during the interview session in order to capture detailed data while concentrating on listening and prompting participants for critical data.

\section{Results and Discussion}

The Information gathered on the demography of the participants shows that out of the 30 participants, 19 were below 30 years of age, while the remaining 11 were 30 years and above. Also, the data showed that there were nine male and 21 female participants. This shows that $70 \%$ of the participants were female, reflecting the world bank statistics which indicate that as of 2019, majority (62.0\%) of teachers in Ghanaian basic schools are female (World Bank Group, 2020).Again, the data shows that 26 of the participants had a Diploma in Education, with the remaining four having a Bachelor's degree awarded by a university. Also, each class level (classes 1, 2, and 3) had 10teachers. Again, the data revealed that 27 of the participants are not professionally trained to teach creative arts, whereas three are professionally trained for the subject. With respect to the length of time in teaching Creative Arts, it was found that 18 participants have been teaching creative arts for five years or less. Another nine have been teaching between six and 10 years, whiles the remaining three have been teaching for more than 10 years. 
Furthermore, all the participantsrevealed that they did not have access to any other teaching resources apart from the approved syllabus, textbooks or activity books. Finally, it was also observed that 22 of the participants taught creative arts lessons once in a week, with the remaining eightindicating that they taught creative arts lessons twice in a week.

Overall, the data gives a vivid description of the participants of the study, revealing that majority of the participants were not adequately trained for teaching creative arts in primary schools. This worrying situation is also coupled with the fact that the participants were not having access to adequate complementary teaching resources for lesson preparation and teaching.

\subsection{Responses from Focused Group Interviews}

After the introduction of the multimedia courseware to the participants as an intervention to the problem, data was collected from the participants through focused group interviews. The themes that emerged from the analysis of participants' comments on the impact of the multimedia courseware on the teaching of Creative Arts in Ghanaian basic schools were: Appropriateness of content of the courseware, Ease of use of the courseware, and Usefulness or Impact of the courseware.

\subsection{Appropriateness of Content of the Courseware}

The data obtained from the participants revealed that the content of the courseware was well structured and appropriate for teaching Creative Arts in the lower primary classes. The comments by some of the participants attest to the fact that the courseware was designed and developed according to the content of the syllabus, and therefore was very appropriate for their lessons.

One of the participants stated that:

The courseware follows the layout of the syllabus so well that I really enjoyed using it for my lesson preparation. Because of this, I did not encounter any difficulty at all in my preparation and it helped me a lot in my teaching. I was very happy with the content. It was very easy to follow and understand (A Participant in Group 1).

Two other participants commented as follows:

I am happy with the work you have done, because it followed the syllabus perfectly. In fact, it even covers more into details than what the syllabushighlights.it think the GES should get in touch with you to design other courseware for other subjects. It is so appropriate for preparation before a class (A Participant in Group 4).

From what I observed during the period of this project, I can say for sure that the courseware is very appropriate for use by all teachers at the basic school level. For example, the terminologies used were explained clearly and made it easy for me to understand the content. I think the courseware is very fit for purpose (A Participant in Group 3).

Another participant indicated that:

Among the many things I like about this courseware, the simplicity of the terminologies is what I like most. This system explains the terminologies and concepts very clearly to my understanding. It is such a good system. I will recommend it to anybody who wants to understand the concepts of creative arts. (A Participant in Group 2).

It is clear from the data that the participants considered the content of the courseware to be appropriate in serving its purpose. This is because the courseware design and development was carried out in a manner that followed the approved syllabus of the Creative Arts, and it adheres to the laid down principle of design which states that in designing courseware and educational materials of this kind, reference should be made to the approved syllabus or course content (Bent \& van den Brink, 2013).

Also, the comments from the participants showed that the terminologies used in the courseware were thoroughly explained to the very minimum levels of understanding. This can be attributed to the fact that the courseware was designed to enable generalist teachers at the lower primary classes understand the concepts clearly and be adequately prepared to teach the creative arts to young children without difficulties.

The finding is consistent with the view of Lawless (2018) who opined that eLearning content developers and instructional designers should aim to make courses clear, easy to understand, and simple to complete. However, care must be taken not to make the content too easy for the comprehension abilities of the learners, since motivation to learn is enhanced when learning tasks are perceived as being interesting and presented at the proper level of difficulty. It must be noted that a task that is too difficult can create frustration, whiles one that is too easy can lead to boredom (National Research Council, 2002).

It is imperative to state that the use of understandable terminologies in the courseware is very important, considering the fact that most of the participants are not professionally trained to teach creative arts. This suggests that when courseware designers and developers refer to and use approved subject syllabi and textbooks, they are most likely to achieve high levels of user acceptability and adoptability.

\subsection{Ease of use of the Courseware}

Results of the study revealed that participants felt at ease with using the courseware. Participants indicated their satisfaction with the ease of use of the courseware. Comments by some of the participants indicated that they were pleased with how easy it is to navigate through the system. 
A participant noted that:

Using the courseware has been very easy for me. When you click on the button, it opens the page without any difficulty at all. And the interface too is very simple and clear(A Participant in Group 2).

Another participant also stated that:

One of the good thingsabout this system is that using it is easy. It doesn't have so many things that makes the navigation easy. The font size too is clear enough so it makes it easy to see. (A Participant in Group 4).

A participant noted that:

Using the courseware has been very easy for me. When you click on the button, it opens the page without any difficulty at all. And the interface too is very simple and clear so it was easy to navigate through the system (A Participant in Group 5).

One other participant mentioned that:

The system is easy to use because the interface is very simple. The buttons are simple too, and the font, the images too are very clear. In fact, the quality of the videos too is very high and up to standard. In all I see the system to be very easy to use. (A Participant in Group 3).

In terms of the ease of using the courseware, it was found out that participants reported that the courseware was very easy to use and to navigate. This result is consistent with the views of Bates (2019) who indicated that an educational program or indeed any Web site should be well structured, intuitive for the user to use, and easy to navigate, because ease of use is a critical factor for technology acceptance and adoption (Teye, 2020).

Furthermore, the result shows that the videos and sound used for the courseware were of very high quality, with very clear coloristic finding suggests that when courseware designers and developers follow the laid down principles of design, with reference to the choice of appropriate colour schemes, appropriate typography, good layout, audible sounds, and quality video recordings, users of the courseware will find it easy to use (Teye, 2012). The finding validates the position of Bates (2019) that when creating materials an educational program for teaching, such features that relate to navigation of the materials, screen layout, graphics and other components of the user interface must be considered only when they will serve a useful educational function. It is important to note that when end users find a piece of technology (such as multimedia courseware) easy to use, they are likely to adopt the technology for use (Davis, 1989; Teye, 2014).

\subsection{Usefulness of the Courseware}

Findings from the analysis of the comments revealed that another major theme that emerged from the data was the usefulness of the courseware on the participants' lesson preparation and delivery. From the data, it was found out that the multimedia courseware had immensely improved the understanding of the participants. This was evident from some of the remarks made by the participants. For instance, two of the participants remarked as follows:

The way I teach creative arts has been greatly improved afterusingthe courseware. Now I am very conversant with many of the terminologies, and this has increased my confidence in teaching creative art lessons to my pupils. It has been a very useful and timely intervention for me. And I think I will recommend it to my colleague teachers if possible (A participant in Group 1).

I find the system very useful and impactful on my teaching. Since I started using this system, I have always felt very ready and prepared to teach my pupils. So, on the whole, I can say that the courseware is very useful. I think it should be upgraded to cover other subject areas for us (A participant in Group 4).

Another participant also stated that:

In fact, I think every teacher should have a feel of this courseware. My way of teaching creative arts has changed for the better, because initially I was only sort of reading out from the activity book and doing some few things that I thought were helping me to teach. But after using this system, I realized that my way of teaching has changed completely. And I know it is because of this system. The thing has been very useful to me. I wish there could be more of these for us teachers. (A Participant in Group 2).

Another participant also stated that:

What I will say is that if anybody want to improve their understanding of the topics in creative arts, they should use this courseware. It Is a very useful thing especially for us in the lower primary classes. The truth is that it is always difficult to teach a subject that you have confidence that you can teach. That was my problem with creative arts. But since this courseware was introduced, I have felt very competent about my teaching strategies. I can say for sure that the software has been very useful and important to me, and I know others too have similar views to share. (A Participant in Group 5).

The comments of the participants show that the courseware has been very useful and impactful to them. This outcome corroborates the findings of Mayer (2005) which states that the use of multimedia courseware in education helps to boost the understanding of users. This suggests that educational institutions must consider the adoption and use of multimedia courseware if they are to attain their educational goals.

Also, the study found out that the deployment of the courseware yielded positive results in assisting the participants in their lesson preparation and delivery. This result supported the assertion that multimedia courseware is very useful for enhancing leaners' understanding of concepts (Verecio, 2014; Xu, 2017). Also, it supports the claim by Rogers (2003) that perceiving an innovation as useful can influence its potential adoption. Again, some participants declared that they will recommend the courseware to their colleagues for their lesson preparation, confirming the point that when users adopt a piece of innovation and find it successful, they are likely to recommend it to other users, as noted by the theory of diffusion of innovation (Rogers, 2003). 


\section{Conclusion and Recommendations}

Summarily, the results of this study give an indication that a multimedia courseware is needed as a guide for teachers in lesson preparation and effective delivery in the creative arts for lower primary pupils in Ghanaian basic schools. The study confirmed the observation that generalist teachers in Ghanaian basic schools lack the competence in teaching the creative arts. However, it was found out that the introduction of the multimedia courseware had a huge positive impact on the teaching strategies and outcomes in teaching the creative arts in Ghanaian basic schools. Therefore, it can be concluded that the deployment of a multimedia courseware was very helpful, due to its significant effect on the teachers and their teaching practices.

The authors wish to recommend that in addition to designing abounding and productive curricular, NaCCA should consider engaging the services of multimedia courseware developers to design and develop courseware for creative arts teachers in Ghanaian basic schools. This consideration should include in-service training packages on multimedia usage for creative arts teachers.

\section{References}

i. Alter, F., Hays, T. \& O'Hara, R. (2009). Creative Arts teaching and practice: Critical reflections of primary school teachers in Australia; International Journal of Education and the Arts, 10(9), 6-7.

ii. Bates, A. W. (2019). Teaching in a digital age: Guidelines for designing teaching and learning (2nd ed.). Retrieved from https://opentextbc.ca/teachinginadigitalage/chapter/9-3-the-sections-model-ease-of-use/

iii. Bent, B. A. \& van den Brink, K. (2013). Multimedia in education curriculum. UNESCO Institute for Information Technologies in Education. Moscow: Russia.

iv. Curriculum Research and Development Division [CRDD] of Ghana. (2007). Teaching syllabus for Creative Arts. Retrieved from http://www.ibe.unesco.org/curricula/ghana/gh_lpr_ar_2007_eng.pdf

v. Davies, F. (1989). Perceived usefulness, perceived ease of use, and user acceptance of information technology. MIS Quarterly, 13(3), 319.

vi. Felder, R. M., \& Brent, R. (2005). Understanding student differences. Journal of engineering education, 94(1), 57-72.

vii. Fletcher, S. (2000). Mentoring in schools: A handbook of good practice. London: Taylor and Francis.

viii. Fu, W., Menzies, T. \& Shen, X. (2016). Tuning for software analytics: Is it really necessary? Information and Software Technology, 76, 135-146.

ix. Gunawardhana, L. K. P. D.\&Palaniappan, S. (2016). Using Multimedia as an Education Tool. Paper presented at the 9th Annual International Conference on Computer Games Multimedia \& Allied Technologies (CGAT 2016), $28^{\text {th }}-30^{\text {th }}$ arch, 2016, Singapore.

x. Joshi, A. (2012). Multimedia: A technique in teaching process in the classrooms. Current World Environment, $7(1), 36$

xi. Judson, E., \& Sawada, D. (2002). Learning from past and present: electronic response Systems in college lecture halls. Journal of Computers in Mathematics and Science Teaching, 21(2), 167-181.

xii. Lawless, C. (2018). The ultimate glossary of eLearning terms. Retrieved from https://www.learnupon.com/blog/elearning-glossary/

xiii. Mayer, R. E. (2005). Cognitive theory of multimedia learning. In R. E. Mayer (Ed.), The Cambridge Handbook of Multimedia Learning. New York: Cambridge University Press.

xiv. Najjar, L. J. (1998). Principles of educational multimedia interface design. Human Factors, 40(2), $311-323$.

xv. National Research Council. (2002). Learning and understanding: Improving advanced study of mathematics and science in U.S. high schools. Committee on Programs for Advanced Study of Mathematics and Science in American High Schools. J. P. Gollub, M. W. Bertenthal, J. B. Labov, and P. C. Curtis (Eds.). Center for Education, Division of Behavioral and Social Sciences and Education. Washington, DC: National Academy Press.

xvi. Nilson, C., Fetherston, C.M., McMurray, A., \& Fetherston T. (2013). Creative arts: an essential element in the teacher's toolkit when developing critical thinking in children. Retrieved from http://ro.ecu.edu.au/cgi/viewcontent.cgi?article=2100\&context=ajte

xvii. Rogers, E. M. (2003). Diffusion of innovations (5th ed.). New York: Free Press.

xviii. Stemler, L. K. (1997). Educational characteristics of multimedia: A literature Review. Journal of Educational Multimedia and Hypermedia, 6(3/4), 339-359.

xix. Taras, M. (2003). To feedback or not to feedback in student self-assessment. Assessment and Evaluation in Higher Education, 28 (5), 549-565.

xx. Tebabal, A. \& Kahssay, G. (2011), The effects of student-centered approach in improving students' graphical interpretation skills and conceptual understanding of kinematical motion. Latin-American Journal of Physics Education, 5(2), 374-381.

xxi. Teye, E. Q. (2014). Computer competences of students with disabilities in the University of Education, Winneba. (Unpublished Master's Thesis). University of Education, Winneba, Ghana.

xxii. Teye, E. Q. (2020). An investigation of contextual factors for the adoption of ICT by headteachers of basic schools. (Unpublished Master's Dissertation). University of Education, Winneba, Ghana.

xxiii. Teye, V. Q. N. (2012). Developing interactive learning system for teaching the elements of design in senior high schools. (Unpublished Master's Thesis). Kwame Nkrumah University of Science and Technology, Kumasi.

xxiv. Ussher, J., Damoah, D., Ansong, D. E., Quarshie, H., Adjetey, C., \&Poakwah, G. (2014). The effectiveness of interactive multimedia courseware as instructional medium for teaching? Retrieved from 
http://www.eajournals.org/wp-content/uploads/The-Effectiveness-of-Interactive-Multimedia-Coursewareas-Instructional-Medium-for-Teaching.pdf

xxv. Verecio, R. L. (2014). Students' evaluation of an interactive multimedia courseware. International Journal of Education and Research, 6(2), 11-22

xxvi. World Bank Group (2020). Trained teachers in primary education (\% of total teachers). Retrieved from https://data.worldbank.org/indicator/SE.PRM.TCAQ.ZS?name_desc=false\&view=map

xxvii. Wren, D. G. (2008). Using formative assessment to increase learning. Research brief No. 1. Department of Research, Evaluation and Assessment. Virginia Beach City Public Schools.

xxviii. Xu, X. (2017). Study on effective using of multimedia teaching system and enhancing teaching effect. International Journal of Emerging Technologies in Learning, 12(6), 187-195. 